\title{
Dissociative Adsorption of Acetone on Platinum Single-Crystal Electrodes
}

\author{
Christoph J. Bondue, Zhiqin Liang, and Marc T. M. Koper*
}

Cite This: J. Phys. Chem. C 2021, 125, 6643-6649

Read Online

ABSTRACT: In this article, we investigate the poisoning reaction that occurs at platinum electrodes during the electrocatalytic hydrogenation of acetone. A better understanding of this poisoning reaction is important to develop electrocatalysts that are both active for the hydrogenation of carbonyl compounds and resilient against poisoning side reactions. We adsorb acetone to $\mathrm{Pt}(331), \mathrm{Pt}(911)$, $\operatorname{Pt}(510)$, and $\operatorname{Pt}(533)$ (i.e., $\operatorname{Pt}[2(111) \times(110)], \operatorname{Pt}[5(100) \times$ (111)], $[5(100) \times(110)]$, and $\mathrm{Pt}[4(111) \times(100)$, respectively $]))$ as well as $\mathrm{Pt}(100)$ single-crystal electrodes and perform reductive and oxidative stripping experiments after electrolyte exchange. We
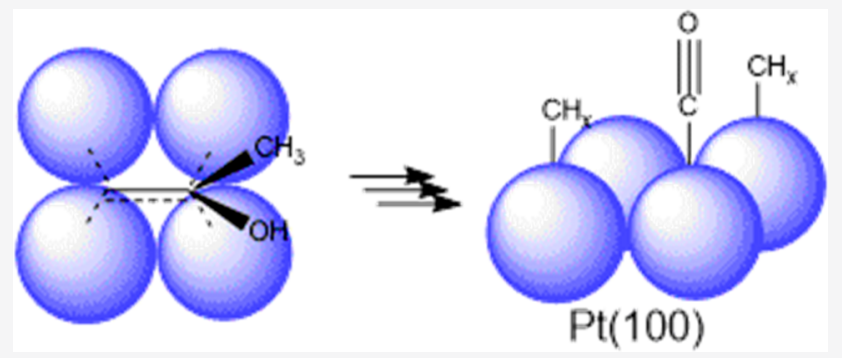
found that acetone adsorbs molecularly intact on all sites apart from $\mathrm{Pt}(100)$ terrace sites and can be stripped reductively from the electrode surface at a potential positive of hydrogen evolution. However, at $\mathrm{Pt}(100)$ terraces, acetone adsorbs dissociatively as carbon monoxide, which remains attached to the electrode surface and leads to its poisoning. Strikingly, dissociative adsorption does not occur on step sites with (100) geometry, which suggests that the dissociative adsorption of acetone is limited to $\mathrm{Pt}(100)$ terraces featuring a certain minimum "ensemble" number of freely available Pt atoms.

\section{INTRODUCTION}

Biomass could become a crucial feedstock for fuels and chemicals in the future. ${ }^{1}$ For that reason, the electrochemical hydrogenation of carbonyl compounds, as a means for the upgrading of pyrolysis $\mathrm{oil}^{2-7}$ or the conversion of 5hydroxymethylfurfural to 2,5-dihydroxymethylfuran or 2,5dimethylfuran, ${ }^{8,9}$ has attracted much attention. Because of the increasing interest in the electrochemical conversion of carbonyl compounds, we recently investigated the electrochemical hydrogenation of acetone as a model compound for more complex carbonyl compounds. ${ }^{10-12}$ In these studies, we found that the nature of the reaction undergone by acetone depends significantly on the crystallographic orientation of the platinum single-crystal electrode. ${ }^{10,11}$ Specifically, no reaction occurs at the $\mathrm{Pt}(111)$ electrode because acetone does not bind to surfaces featuring high coordination numbers. ${ }^{10,11}$ The hydrogenation of acetone occurs only at step sites, whereas the step geometry determines whether the reaction yields 2propanol or propane. ${ }^{10,13,14}$ Finally, a reaction occurs at $\mathrm{Pt}(100)$ terraces that leads to poisoning. ${ }^{10}$ Understanding the latter reaction is important for catalyst development because an electrocatalyst that is highly active for the electrochemical hydrogenation of carbonyl compounds is useless if active surface sites are poisoned by reactions occurring at other surface sites.

Previous experiments have revealed that ethyl pyruvateanother carbonyl compound-adsorbs under decarbonylation (that is, CO formation) at all platinum surfaces, ${ }^{15}$ whereas stripping experiments suggest that decarbonylation occurs mainly on $\mathrm{Pt}(100)$ electrodes. $^{6}$ In the present work, acetone is adsorbed to a variety of platinum single-crystal electrodes. After electrolyte exchange under potential control, stripping experiments under both reductive and oxidative conditions are conducted. These experiments show that nondissociative acetone adsorption occurs on all step sites, from which the adsorbate can be stripped reductively prior to hydrogen evolution and oxidatively in the potential range of platinum oxide formation. This is also true for step sites with a (100) geometry. Decarbonylation takes place only at the $\mathrm{Pt}(100)$ electrode, which we derive from both the stripping behavior of the formed adsorbate and surface-enhanced raman spectroscopy (SERS) as well as Fourier transform infrared (FTIR) spectroscopy measurements. In accordance with Hazzazi et al., ${ }^{6}$ we conclude that dissociative acetone adsorption requires a (100) geometry featuring more than two neighboring platinum atoms.

\section{EXPERIMENTAL SECTION}

Chemicals and Materials. The blank electrolyte was prepared from Milli-Q water, $\mathrm{H}_{2} \mathrm{SO}_{4}$ (suprapure, Merck), and

Received: December 21, 2020

Revised: March 1, 2021

Published: March 18, 2021 
acetone (HPLC grade, Sigma-Aldrich). All solutions were freed from oxygen by purging with argon (6.0, Linde). Potentials were measured versus a reversible hydrogen electrode (RHE) in contact with the blank electrolyte. A platinum wire was used as a counter electrode. The used beadtype single crystals were obtained from iCryst. Cyclic voltammograms (CV) were recorded on an Iviumstat potentiostat (Ivium Technologies). The used glassware was kept in acidic permanganate solution for at least $8 \mathrm{~h}$. Prior to use, the glassware was rinsed with acidic peroxide solution and boiled several times in Milli-Q water.

Electrolyte Exchange Experiments. Prior to every experiment, the single-crystal electrode was prepared by the Clavilier method ${ }^{16}$ and the quality of the preparation was checked by recording a CV in the blank electrolyte. Next, the electrode was transferred to a second cell filled with roughly $20 \mathrm{~mL}$ of the acetone containing electrolyte $\left(0.1 \mathrm{M} \mathrm{H}_{2} \mathrm{SO}_{4}\right.$ containing $10 \mathrm{mM}$ of acetone). The electrode was immersed at the indicated potential, and acetone adsorption was allowed to take place for $1 \mathrm{~min}$. Afterward, the electrolyte was slowly let out through a stopcock at the bottom of the cell, while the blank electrolyte $\left(0.1 \mathrm{M} \mathrm{H}_{2} \mathrm{SO}_{4}\right)$ was filled simultaneously from the top of the cell. During this period the contact between the working electrode, the reference electrode, and the counter electrode is maintained so that the electrolyte exchange proceeds under controlled potential. Therefore, reactions that might occur when the electrode is transferred through air or when it goes to open-circuit potential can be ruled out. After a time period of approximately $15 \mathrm{~min}$, a volume of $200 \mathrm{~mL}$ was flushed through the cell. At this point, the acetone content in the electrolyte was deemed negligible and the electrode is brought into the hanging meniscus configuration to conduct the potential sweep.

Surface-Enhanced Raman Spectroscopy (SERS). Electrodes used for SERS studies were prepared by a protocol established by Zou and Weaver: ${ }^{17}$ First, a polycrystalline gold electrode is roughened by 20 cycles of potential steps between $1.2(5 \mathrm{~s})$ and $-0.6 \mathrm{~V}(20 \mathrm{~s}) \mathrm{vs} \mathrm{Ag} / \mathrm{AgCl}$ in a solution of $0.5 \mathrm{M}$ $\mathrm{KCl}$. Galvanostatic platinum deposition is conducted with a current density of $400 \mu \mathrm{A} / \mathrm{cm}^{2}(20 \mathrm{~s})$ from a solution of $100 \mu \mathrm{M} \mathrm{H}_{2} \mathrm{PtCl}_{6}$ in $0.35 \mathrm{M} \mathrm{Na}_{2} \mathrm{HPO}_{4}$. SERS spectra of this electrode were collected with a LabRam HR800 (Horiba Jobin Yvon) confocal microscope, which featured a $\mathrm{HeNe}$ laser $(632.81 \mathrm{~nm})$. A detailed description of the setup and the methodology has been given elsewhere. ${ }^{18}$ Each spectrum shown is the average of 4 spectra. The background of the spectra was recorded after the stripping experiment at the same potential and was subtracted from the spectra recorded with the preabsorbed acetone.

In Situ FTIR Spectroscopy. FTIR spectra were recorded on Vertex V80 (Bruker). The used FTIR cell was home built and featured a $\mathrm{CaF}_{2}$ prism. ${ }^{19}$ Single-crystal electrodes with a diameter of $1 \mathrm{~cm}$ were pressed onto the prism to achieve a thin gap between the electrode and the prism. A background spectrum was recorded at either 0.8 or $0.4 \mathrm{~V}$ (vs RHE) followed by a step to the indicated potential, where another spectrum was recorded, from which the background spectrum was subtracted. All spectra were recorded with a resolution of $8 \mathrm{~cm}^{-1}$ and are the average over 200 interferograms using ppolarized light. Spectra are presented as absorbance. Therefore, positive bands indicate formation of a species, while negative bands indicate consumption of a species.

\section{RESULTS}

Acetone Adsorption at $\mathrm{Pt}(111)$. We have shown previously that acetone reduction does not take place at the $\mathrm{Pt}(111)$ electrode. ${ }^{10,11}$ This conclusion can be derived again from the CVs in Figure 1. The black CV was taken at a

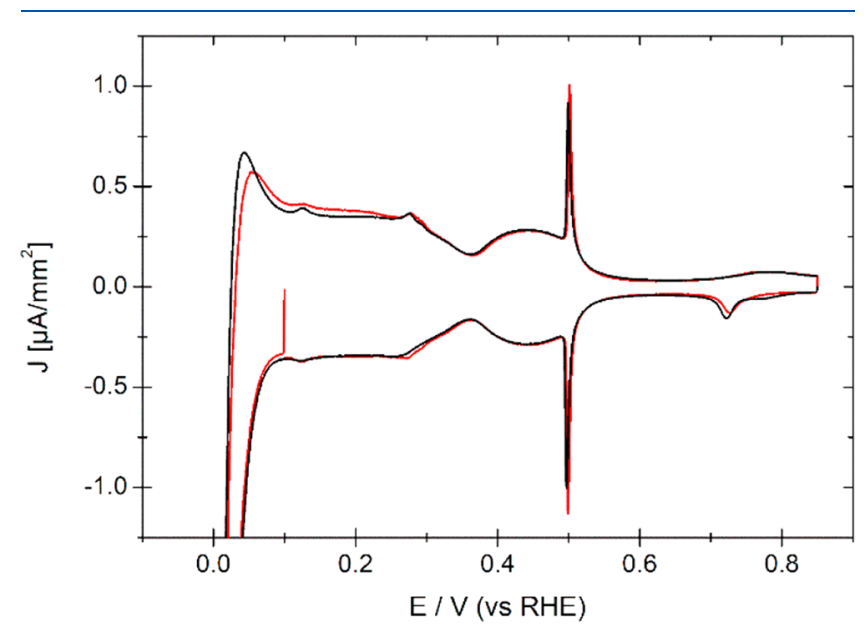

Figure 1. $\mathrm{CV}$ of $\mathrm{Pt}(111)$ in $0.1 \mathrm{M} \mathrm{H}_{2} \mathrm{SO}_{4}$ (black) and $0.1 \mathrm{M} \mathrm{H}_{2} \mathrm{SO}_{4}$ containing $10 \mathrm{mM}$ acetone (red). Sweep rate: $50 \mathrm{mV} / \mathrm{s}$.

$\mathrm{Pt}(111)$ electrode in the blank electrolyte of $0.1 \mathrm{M} \mathrm{H}_{2} \mathrm{SO}_{4}$, while the red $\mathrm{CV}$ was taken when $10 \mathrm{mM}$ acetone was added to the electrolyte. Both CVs are nearly identical. In particular, the sulfate spike due to the rearrangement of the sulfate adlayer is not affected by the presence of acetone. As this process is rather sensitive to the presence of other adsorbates, the sharpness of the sulfate spike in the red curve of Figure 1 shows that no adsorption of acetone occurs.

Acetone Adsorption at $\operatorname{Pt}(331)$ (i.e., $\operatorname{Pt}[2(111) \times$ (110)]). The situation changes when a $\operatorname{Pt}(331)$ (i.e., $\mathrm{Pt}[2(111) \times(110)])$ electrode is used, where $(111)$ terraces of only two atoms width are interrupted by (110) steps. The black curve in Figure 2 shows the $\mathrm{CV}$ of the $\mathrm{Pt}(331)$ (i.e., $\mathrm{Pt}[2(111) \times(110)])$ electrode in an $0.1 \mathrm{M} \mathrm{H}_{2} \mathrm{SO}_{4}$ electrolyte.

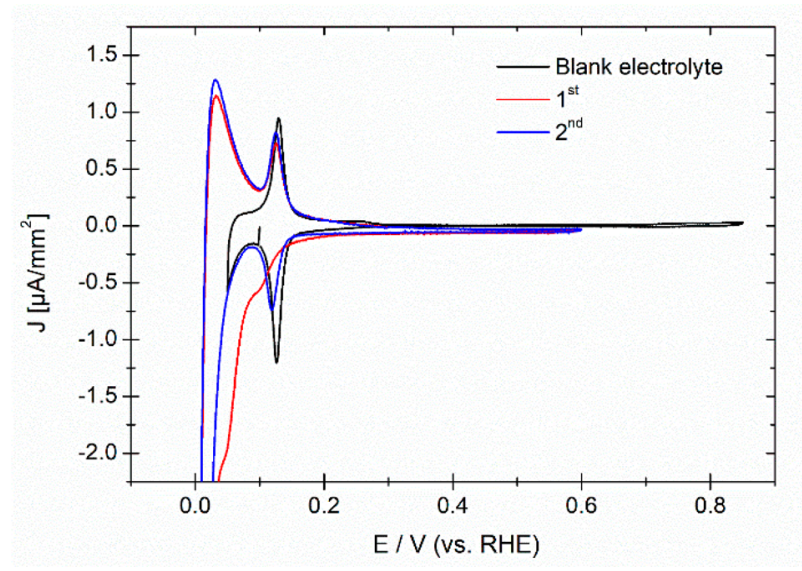

Figure 2. $\mathrm{CV}$ of $\mathrm{Pt}(331)$ (i.e., $\mathrm{Pt}[2(111) \times(110)]$ in $0.1 \mathrm{M} \mathrm{H}_{2} \mathrm{SO}_{4}$. Black: blank CV immediately after preparation. Red: first cycle after acetone adsorption at $0.3 \mathrm{~V}$ (vs RHE) and electrolyte exchange under potential control. Blue: subsequent, second, cycle. Sweep rate: $50 \mathrm{mV} / \mathrm{s}$. Blue and red curves: lower potential limit is $0.0 \mathrm{~V}$ (vs RHE). (CVs of $\mathrm{Pt}(331)$ (i.e., $\mathrm{Pt}[2(111) \times(110)])$ to $0 \mathrm{~V}$ in the blank electrolyte can be found in the Supporting Information of ref 10.) 
The reversible peak at $0.12 \mathrm{~V}$ (vs RHE) corresponds to the replacement of adsorbed hydrogen by adsorbed hydroxyl at the $\mathrm{Pt}(110)$ step sites. ${ }^{20}$ The red curve in Figure 2 is the CV obtained at the same electrode after exposure to an acetonecontaining electrolyte at $0.3 \mathrm{~V}$ (vs RHE) and subsequent electrolyte exchange under potential control to $0.1 \mathrm{M} \mathrm{H}_{2} \mathrm{SO}_{4}$. In the first negative-going scan, hydrogen/hydroxyl adsorption and desorption at $0.12 \mathrm{~V}$ (vs RHE) is largely blocked, indicating that the (110) step sites are covered by an acetonederived adsorbate. Prior to hydrogen evolution a shoulder appears at around $0.05 \mathrm{~V}$ (vs RHE), which has been associated previously with the reduction of acetone to 2-propanol. ${ }^{10}$ After the first negative-going sweep, hydrogen/hydroxyl adsorption and desorption at the $\mathrm{Pt}(110)$ step sites is possible again, which is shown by the blue curve in Figure 2. Since reductive stripping of acetone as 2-propanol is only possible when no bonds have been cleaved upon adsorption of acetone, we conclude that acetone adsorbs to the $\mathrm{Pt}(331)$ (i.e., $\mathrm{Pt}[2(111)$ $\times(110)])$ electrode with its molecular structure intact.

Figure 3 shows that reductive stripping of acetone removes nearly all adsorbates from the $\operatorname{Pt}(331)$ (i.e., $\operatorname{Pt}[2(111) \times$

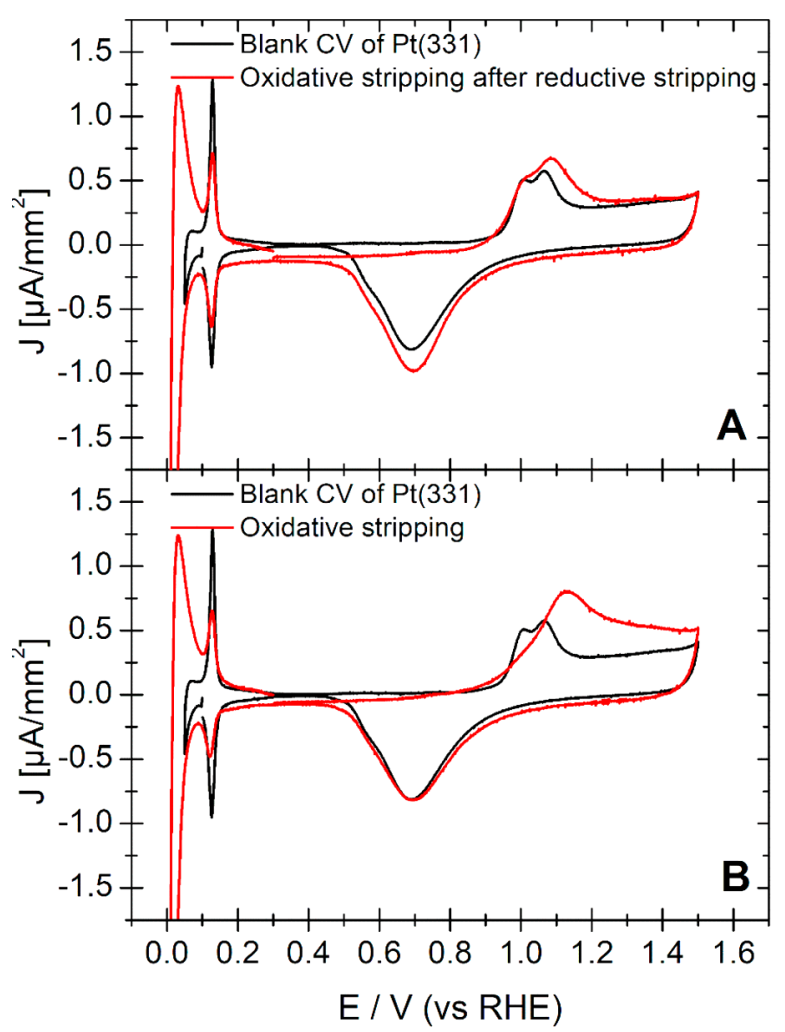

Figure 3. $\mathrm{CV}$ of $\mathrm{Pt}(331)$ (i.e., $\mathrm{Pt}[2(111) \times(110)])$ in $0.1 \mathrm{M} \mathrm{H}_{2} \mathrm{SO}_{4}$. Black: immediately after preparation. Red: Oxidative stripping experiment. (A) Stripping experiment conducted immediately after the reductive stripping experiment of Figure 2. (B) Stripping experiment conducted after preadsorption of acetone and electrolyte exchange. Sweep rate: $50 \mathrm{mV} / \mathrm{s}$. Red curves: lower potential limit is $0.0 \mathrm{~V}$ (vs RHE).

(110)]) surface. The red curve shows the first sweep to $1.5 \mathrm{~V}$ (vs RHE) after the reductive stripping experiment of Figure 2 was conducted. Compared to the black curve of Figure 3A, which is the $\mathrm{CV}$ of the $\mathrm{Pt}(331)$ electrode (i.e., $\operatorname{Pt}[2(111) \times$ (110)]) in the blank electrolyte, barely any additional charge is transferred in the red $\mathrm{CV}$. However, there might be some contributions due to the oxidation of impurities that have adsorbed along with acetone during the electrolyte exchange (ca. 15 min duration) or from 2-propanol that reabsorbs after the stripping experiment.

The absence of a significant additional oxidation current in the red curve of Figure $3 \mathrm{~A}$ indicates that no additional oxidation of an irreducible adsorbate has taken place. Hence, acetone only forms an adsorbate that is stripped reductively from the electrode surface. Other adsorbates such as CO formed from the decarbonylation of acetone ${ }^{10,14}$ are not present at the $\operatorname{Pt}(331)$ electrode (i.e., $\operatorname{Pt}[2(111) \times(110)])$.

In Figure 3 the sharpness of the peak due to hydrogen/ hydroxyl adsorption and desorption at the $\mathrm{Pt}(110)$ step sites has reduced significantly after exploring a potential of $1.5 \mathrm{~V}$ (vs RHE). This is due to the formation and subsequent reduction of platinum oxide, which introduces defects into the platinum surface. ${ }^{21}$ In the CVs of other electrodes shown later in this article and in the Supporting Information, peaks associated with a pristine electrode surface with specific orientation will lose sharpness or disappear when a potential of $1.5 \mathrm{~V}$ (vs $\mathrm{RHE}$ ) is applied.

In Figure $3 \mathrm{~B}$ the red curve is the first $\mathrm{CV}$ of the $\mathrm{Pt}(331)$ electrode (i.e., $\mathrm{Pt}[2(111) \times(110)])$ after acetone adsorption at $0.3 \mathrm{~V}$ (vs RHE) and subsequent exchange of the electrolyte to $0.1 \mathrm{M} \mathrm{H}_{2} \mathrm{SO}_{4}$ under potential control but now avoiding the reductive acetone stripping, so that the (110) step sites remain covered with acetone. The additional charge passed in the potential region of platinum oxide formation corresponds therefore to the oxidation of acetone that is adsorbed with an intact molecular structure. This is supported by the results presented by Bänsch et al., who conducted acetone-stripping experiments with polycrystalline platinum electrodes. On the basis of their DEMS results they concluded that the adsorbate oxidized in the potential range of platinum oxide formation is acetone. $^{14}$

Acetone Adsorption at $\mathrm{Pt}(100)$. Figure 4 shows results of reductive acetone stripping on $\mathrm{Pt}(100)$. The black curve shows the $\mathrm{CV}$ of a $\mathrm{Pt}(100)$ electrode in $0.1 \mathrm{M} \mathrm{H}_{2} \mathrm{SO}_{4}$. The reversible peak at $0.4 \mathrm{~V}$ (vs RHE) is due to the adsorption and desorption of hydrogen at the (100) terraces. The red curve in

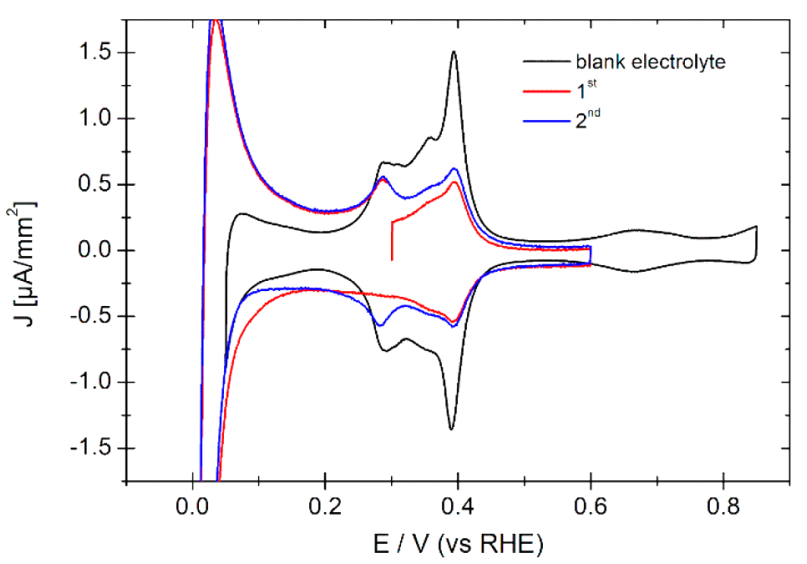

Figure 4. $\mathrm{CV}$ of $\mathrm{Pt}(100)$ in $0.1 \mathrm{M} \mathrm{H}_{2} \mathrm{SO}_{4}$. Black curve: blank $\mathrm{CV}$ immediately after preparation. Red curve: first cycle after acetone adsorption at $0.3 \mathrm{~V}$ (vs RHE) and electrolyte exchange under potential control. Blue curve: second cycle. Sweep rate: $50 \mathrm{mV} / \mathrm{s}$. Blue and red curves: lower potential limit is $0.0 \mathrm{~V}$ (vs RHE). (CVs of $\mathrm{Pt}(100)$ to $0 \mathrm{~V}$ in the blank electrolyte can be found in the Supporting Information of ref 10.) 
Figure 4 is the first $\mathrm{CV}$ of the same $\mathrm{Pt}(100)$ electrode after exposure to an acetone-containing electrolyte at $0.3 \mathrm{~V}$ (vs RHE) and subsequent exchange of the electrolyte to $0.1 \mathrm{M}$ $\mathrm{H}_{2} \mathrm{SO}_{4}$ under potential control. Starting from $0.3 \mathrm{~V}$ (vs RHE), the potential is first scanned to $0.6 \mathrm{~V}$ (vs RHE) and from there back to $0.0 \mathrm{~V}$ (vs RHE). Hydrogen adsorption at (100) terrace sites is hindered in both the positive- and the negative-going potential scan, indicating the presence of an adsorbate. Only a faint shoulder due to the reductive stripping of acetone from defect sites appears prior to hydrogen evolution (cf. electrolyte exchange experiments at $\mathrm{Pt}(911)$ (i.e., $\mathrm{Pt}[5(100) \times(111)]$ ) and $\operatorname{Pt}(510)$ (i.e., $\operatorname{Pt}[5(100) \times(110)])$ discussed in the Supporting Information). Reductive stripping of acetone from $\mathrm{Pt}(100)$ terraces can be excluded, since hydrogen adsorption and desorption at the (100) terraces remains hindered in the second scan (blue curve) of Figure 4. Obviously the adsorbate at the $\mathrm{Pt}(100)$ electrode cannot be stripped from the electrode surface under reductive conditions and remains adsorbed.

This is also clear from Figure 5A, where the red curve shows the first sweep to a potential of $1.5 \mathrm{~V}$ (vs RHE) after the reductive stripping experiment of Figure 4 was conducted. Compared to the $\mathrm{CV}$ of the same electrode without preexposure to acetone (black curve), additional charge is passed in the potential range between 0.6 (vs RHE) and $0.9 \mathrm{~V}$ (vs RHE) prior to platinum oxide formation. This charge must

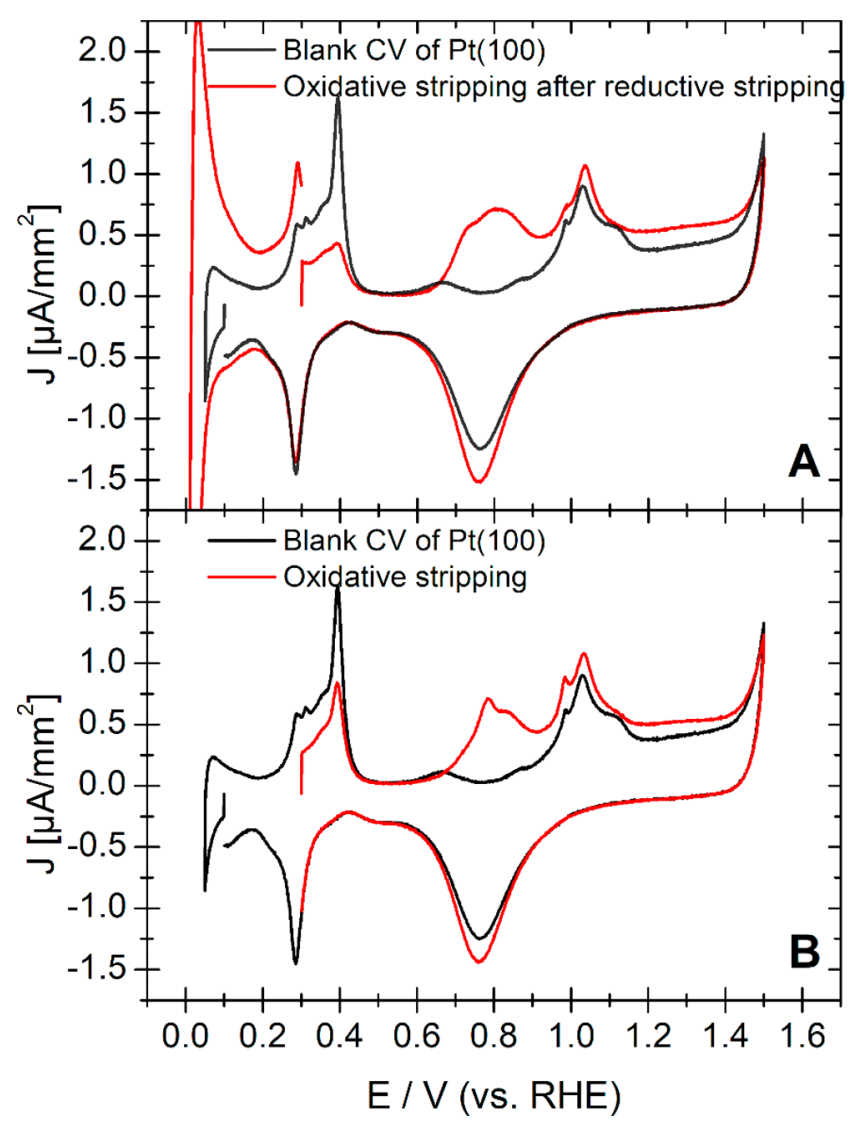

Figure 5. $\mathrm{CV}$ of $\mathrm{Pt}(331)$ (i.e., $\mathrm{Pt}[2(111) \times(110)])$ in $0.1 \mathrm{M} \mathrm{H}_{2} \mathrm{SO}_{4}$. Black: immediately after preparation. Red: Oxidative stripping experiment. (A) Stripping experiment conducted immediately after the reductive stripping experiment of Figure 4. (B) Stripping experiment conducted after preadsorption of acetone and electrolyte exchange. Sweep rate: $50 \mathrm{mV} / \mathrm{s}$. Red curve in A: lower potential limit is $0.0 \mathrm{~V}$ (vs RHE). be due to the oxidative stripping of the adsorbate that blocks hydrogen adsorption at the $\mathrm{Pt}(100)$ terrace sites. However, this adsorbate is not acetone as the oxidative stripping of the latter occurs in the potential range of platinum oxide formation $^{14}$ (cf. also the stripping experiment in Figure 3A). Furthermore, it is improbable that acetone is adsorbed intact to the $\mathrm{Pt}(100)$ surface, as this is thermodynamically unfavorable. ${ }^{10}$ However, it is well documented that acetaldehyde adsorbs via cleavage of the $\mathrm{C}-\mathrm{C}$ bond as $\mathrm{CO}$ and $\mathrm{CH}_{x}$ species to Pt electrodes. ${ }^{18,22-24}$ It appears therefore likely that the decarbonylation of acetone at $\mathrm{Pt}(100)$ leads to a $\mathrm{CO} / \mathrm{CH}_{x^{-}}$ covered surface. Also, the stripping behavior observed in Figures 4 and $5 \mathrm{~A}$ fits the occurrence of the decarbonylation reaction, that is, the products of this reaction, particularly $\mathrm{CO}$, would not be stripped reductively in the potential region prior to hydrogen evolution but are oxidized in the double-layer region. The voltammetry of the stripping experiment follows the general behavior observed for corresponding experiments with acetaldehyde. ${ }^{25}$ This differs somewhat from the stripping of a pure saturated $\mathrm{CO}$ layer, which occurs in a sharp peak. However, stripping of the formed adsorbates requires also the conversion of $\mathrm{CH}_{x}$ species to $\mathrm{CO}$, which occurs at $0.4 \mathrm{~V},{ }^{25}$ and explains why stripping in Figures 4 and $5 \mathrm{~A}$ does not occur in the sharp peak expected for pure $\mathrm{CO}$. We therefore conclude that acetone undergoes dissociative adsorption at $\mathrm{Pt}(100)$ surface sites, resulting in the formation of adsorbed $\mathrm{CO}$ and $\mathrm{CH}_{x}$ species, with the latter reacting to $\mathrm{CO}$ as well at sufficiently positive potential. ${ }^{25}$ This interpretation is also supported by our SERS experiments (vide infra).

The oxidative stripping of $\mathrm{CO}$ from the $\mathrm{Pt}(100)$ electrode is not affected by a previous sweep into the hydrogen evolution region. This is shown in Figure 5B, where the oxidative stripping is conducted immediately after the electrolyte exchange to $0.1 \mathrm{M} \mathrm{H}_{2} \mathrm{SO}_{4}$. The $\mathrm{CV}$ does not change significantly compared to that observed in Figure 5A, where the electrode was exposed to $0 \mathrm{~V}$ in the previous experiment (cf. Figure 4), that is, in both CVs $\mathrm{CO}$ is oxidized in the potential region between 0.6 (vs RHE) and $0.9 \mathrm{~V}$ (vs RHE). Hence, the formation of acetone-derived $\mathrm{CO}$ occurs immediately during adsorption at $0.3 \mathrm{~V}$ (vs RHE) and does not form when the potential is swept into the potential region where at other platinum surfaces acetone reduction proceeds. Comparison of the red curves in Figure 5A and 5B shows, therefore, that the lower potential limit does not affect the decarbonylation reaction.

After the electrolyte exchange experiment, there is no significant additional charge in the potential region of platinum oxide formation (red curves of Figure 5) compared to the experiment conducted without exposure to acetone (black curve in Figure 5). A small additional charge might be due to adsorbates other than acetone that have formed during the long exposure time of the electrolyte exchange experiment. This suggests that all of the acetone-derived adsorbates are stripped at potentials below $0.9 \mathrm{~V}$ and that acetone undergoes complete decarbonylation at the $\mathrm{Pt}(100)$ electrode. However, considering the accuracy of our experiment, we cannot rule out that acetone forms some adsorbates at $\mathrm{Pt}(100)$ electrodes that are stripped in the potential region of $\mathrm{Pt}$-oxide formation.

The same stripping experiments discussed for $\mathrm{Pt}(331)$ (i.e., $\operatorname{Pt}[2(111) \times(110)])$ and $\operatorname{Pt}(100)$ were also conducted for $\operatorname{Pt}(911), \operatorname{Pt}(510)$, and $\operatorname{Pt}(533)$ (i.e., $\operatorname{Pt}[5(100) \times(111)]$, $[5(100) \times(110)]$, and $\mathrm{Pt}[4(111) \times(100)$, respectively $])$. The relevant $\mathrm{CVs}$ and the related discussion can be found in the 
Supporting Information $(\mathrm{Pt}(911)$ (i.e., $\mathrm{Pt}[5(100) \times(111)])$ : Figures S1 and S2; $\mathrm{Pt}(510)$ (i.e., $\mathrm{Pt}[5(100) \times(110)])$ : Figures S3 and S4; Pt(533) (i.e., Pt[4(111) × (100)): Figures S5 and S6). In addition, these experiments indicate that decarbonylation of acetone occurs at $\mathrm{Pt}(100)$ terraces sites (cf. $\mathrm{Pt}(510)$ (i.e., $\operatorname{Pt}[5(100) \times(110)]), \operatorname{Pt}(911)$ (i.e., $\operatorname{Pt}[5(100) \times$ $(111)])$ ), whereas acetone adsorbed at step sites can be stripped reductively. This is particularly remarkable for acetone adsorbed at the (100) step sites of $\operatorname{Pt}(533)$ (i.e., $\operatorname{Pt}[4(111) \times$ (100)). The fact that no decarbonylation is observed at this surface site indicates that acetone decarbonylation requires not only a specific surface geometry but also that it has to be of extended size.

Surface-Enhanced Raman Spectra of Preabsorbed Acetone at Polycrystalline Platinum. Figure 6 shows the

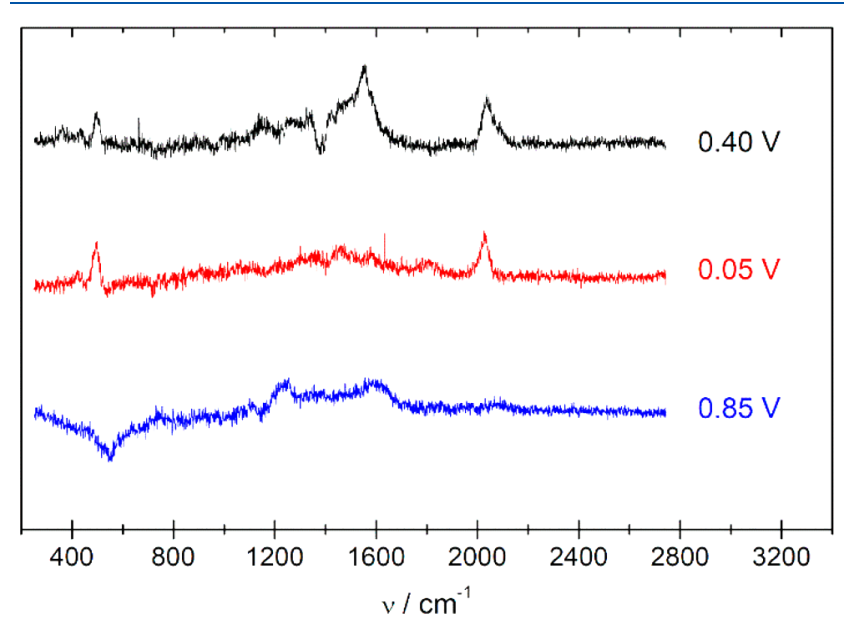

Figure 6. SER spectra of acetone preabsorbed at $0.4 \mathrm{~V}$ (vs RHE) to a polycrystalline $\mathrm{Pt}$ electrode. Spectra were recorded after the electrolyte of $0.1 \mathrm{M} \mathrm{H}_{2} \mathrm{SO}_{4}$ containing $10 \mathrm{mM}$ acetone was exchanged to the blank electrolyte under potential control. Black curve: recorded at $0.4 \mathrm{~V}$ (vs RHE). Red curve: recorded at $0.05 \mathrm{~V}$ (vs RHE). Blue curve: recorded at $0.85 \mathrm{~V}$ (vs RHE). Spectra were background corrected by spectra recorded after the stripping experiment at the same potential.

SER spectra obtained at a polycrystalline Pt electrode when the electrolyte exchange experiment is conducted, that is, the electrode is initially exposed at $0.4 \mathrm{~V}$ (vs RHE) to an electrolyte of $0.1 \mathrm{M} \mathrm{H}_{2} \mathrm{SO}_{4}$ containing $10 \mathrm{mM}$ acetone. Afterward, the electrolyte is exchanged under potential control to the blank electrolyte, and a set of SERS spectra is recorded.

The black curve in Figure 6 shows two very prominent bands at 1556 and $2035 \mathrm{~cm}^{-1}$ and two smaller bands at 431 and $492 \mathrm{~cm}^{-1}$. We assign the band at $1556 \mathrm{~cm}^{-1}$ to the $\mathrm{C}=\mathrm{O}$ stretching vibration of adsorbed acetone. The severe red shift of $151 \mathrm{~cm}^{-1}$ compared to the $\mathrm{C}=\mathrm{O}$ stretching vibration of free acetone (at $1707 \mathrm{~cm}^{-126}$ ) indicates a significant weakening of the carbonyl bond when acetone interacts with the platinum surface. This weakening is much more intense in our experiments than indicated by RAIR spectra of acetone adsorbed in a vacuum to the $\mathrm{Pt}(111)$ surface, where a band due to the $\mathrm{C}=\mathrm{O}$ stretching vibration appears at $1636 \mathrm{~cm}^{-1}$. $^{27}$ However, under UHV conditions acetone adsorbs via the $\eta^{1}(\mathrm{O})$ end-on geometry where the carbonyl oxygen interacts with the platinum surface. ${ }^{27-29}$ Although the enol tautomer binding in a $\mu^{2}\left(\mathrm{C}_{1}, \mathrm{C}_{2}\right)$ side-on geometry via the $\mathrm{C}=\mathrm{C}$ bond is more stable by $40 \mathrm{~kJ} / \mathrm{mol}$ than the $\eta^{1}(\mathrm{O})$ configuration of the keto tautomer, ${ }^{28,29}$ the former adsorption mode is not realized in vacuum because the intramolecular hydrogen rearrangement to the enol tautomer is inhibited due to the kinetic barrier of this reaction. ${ }^{28}$ In an acidic, aqueous electrolyte hydrogen rearrangement can proceed via an intermolecular (instead of an intramolecular) mechanism, which should lower the activation barrier for enol tautomerization significantly. Hence, we expect that acetone adsorbs in our experiments as the enol tautomer in the $\mu^{2}\left(\mathrm{C}_{1}, \mathrm{C}_{2}\right)$ side-on geometry. This is consistent with our former experiments on the $\mathrm{H} / \mathrm{D}$ exchange of adsorbed acetone. ${ }^{12,14}$ Furthermore, DFT calculations suggest that a band due to the $\mathrm{C}-\mathrm{O}$ stretching vibration of the enolate of acetone should appear at $1574 \mathrm{~cm}^{-1}$ when adsorbed at the $\mathrm{Pt}(111)$ surface. ${ }^{28,29}$ This compares well with the band at $1556 \mathrm{~cm}^{-1}$ in the SER spectra of Figure 6 . The remaining bands can be assigned to the $\mathrm{C}=\mathrm{O}$ stretching vibration (at $2035 \mathrm{~cm}^{-1}$ ) and to the $\mathrm{Pt}-\mathrm{C}$ stretching vibration (at 431 and at $492 \mathrm{~cm}^{-1}$ ) of adsorbed $\mathrm{CO} .^{25}$ As the potential is stepped to $0.05 \mathrm{~V}$ (vs RHE) (red curve of Figure 6), the bands associated with adsorbed acetone disappear while the bands due to adsorbed CO remain present. The latter only disappear when the potential is stepped to $0.85 \mathrm{~V}$ (vs RHE) (blue curve of Figure 6).

Considering that the SER spectra are recorded at a rough polycrystalline Pt electrode, it is difficult to determine based on spectral data alone at which surface sites $\mathrm{CO}$ and acetone are adsorbed. However, in the SERS experiments acetone is stripped from the electrode surface when a potential of $0.05 \mathrm{~V}$ (vs RHE) is applied. Similarly, our electrolyte exchange experiment show that acetone preabsorbed at stepped Pt single crystals can be stripped reductively in the same potential region. We assign, therefore, the band at $1556 \mathrm{~cm}^{-1}$ to the $\mathrm{C}=\mathrm{O}$ stretching vibration of acetone adsorbed to step sites. On the other hand, adsorbates formed at the $\mathrm{Pt}(100)$ electrode can only be removed from the electrode surface via oxidative stripping. This behavior is mirrored by $\mathrm{CO}$ in our SERS experiment, and we therefore conclude that the adsorbate formed on $\mathrm{Pt}(100)$ terraces sites is $\mathrm{CO}$.

This interpretation is further supported by our FTIR data. Figure 7 shows for each basal plane of platinum FTIR spectra

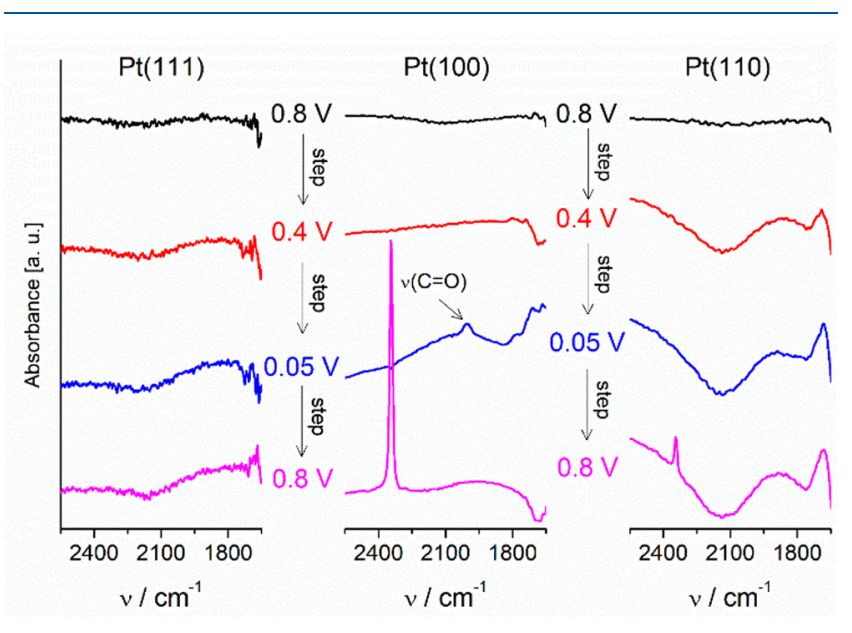

Figure 7. FTIR spectra obtained in an electrolyte of $0.1 \mathrm{M} \mathrm{H}_{2} \mathrm{SO}_{4}$ containing $10 \mathrm{mM}$ acetone at $\mathrm{Pt}(111)$ (left), at $\mathrm{Pt}(100)$ (center), and at $\operatorname{Pt}(110)$ (right). First spectrum and background were obtained at $0.8 \mathrm{~V}$ (vs RHE) (black) and the following after steps to $0.4 \mathrm{~V}$ (vs RHE) (red), $0.05 \mathrm{~V}$ (blue), and back to $0.8 \mathrm{~V}$ (vs RHE). 
in the frequency range between 1900 and $2500 \mathrm{~cm}^{-1}$. The first spectra at each basal plane were obtained at $0.8 \mathrm{~V}$ (vs RHE) (black curves) followed by spectra obtained after a step to $0.4 \mathrm{~V}$ (vs RHE) (red curves), to $0.05 \mathrm{~V}$ (vs RHE) (blue curves), and back to $0.8 \mathrm{~V}$ (vs RHE) (magenta curves). Neither at the $\mathrm{Pt}(111)$ nor at the $\mathrm{Pt}(110)$ electrode is a a band around $2000 \mathrm{~cm}^{-1}$ observed, indicative for the formation of CO. However, after a step to $0.05 \mathrm{~V}$ (vs RHE), the appearance of a band at $2012 \mathrm{~cm}^{-1}$ reveals the formation of adsorbed $\mathrm{CO}$ at the $\mathrm{Pt}(100)$ electrode. After a step to $0.8 \mathrm{~V}$ (vs RHE), the adsorbed $\mathrm{CO}$ is oxidized to $\mathrm{CO}_{2}$, which is observed in the magenta spectra of the $\mathrm{Pt}(100)$ electrode as a sharp band at $2341 \mathrm{~cm}^{-1}$. Hence, in the FTIR experiments of Figure 7, decarbonylation occurs only at the $\operatorname{Pt}(100)$ electrode to a detectable degree, which supports the results derived from the electrolyte exchange experiments.

It is worth mentioning that the FTIR spectra of Figure 7 were recorded in fast succession, whereas the electrolyte exchange experiments and the recording of the SERS data require a longer time. This combined with slow kinetics of the decarbonylation reaction of acetone is probably the reason why we observe at $0.4 \mathrm{~V}$ (vs RHE) a strong band in the SERS spectra due to adsorbed $\mathrm{CO}$; the $\mathrm{CO}$ band in the corresponding FTIR spectra is rather weak.

We show in Figures S7-S9, Supporting Information, FTIR spectra obtained at each basal plane of platinum after exposure of the electrode at $0.4 \mathrm{~V}$ (vs RHE) to the acetone-containing electrolyte for $1 \mathrm{~h}$. Under these conditions the formation of $\mathrm{CO}$ is observed at all platinum basal planes. However, we do not interpret these results as an indication that decarbonylation of acetone occurs on all platinum surfaces. In light of the CV results obtained at bead-type single crystals after electrolyte exchange we believe that the $\mathrm{CO}$ observed in the FTIR spectra at $\mathrm{Pt}(111)$ and $\mathrm{Pt}(110)$ in Figures $\mathrm{S} 7$ and $\mathrm{S} 9$ is formed at defects from which it migrates over the entire surface, that is, the crystals used to collect the FTIR spectra are rich in defects since they are pressed regularly and rather forcefully onto the FTIR prism.

\section{DISCUSSION}

Adsorbed $\mathrm{CO}$ forms on $\mathrm{Pt}(100)$ terrace sites, but it will poison other sites as well. Since adsorbed CO is mobile, ${ }^{30}$ it migrates away from $\mathrm{Pt}(100)$ terraces and occupies preferentially Pt step sites. Step sites are the active surface sites for acetone reduction but will be poisoned by the formation of $\mathrm{CO}$ elsewhere. Therefore, decarbonylation of acetone, although limited to extended $\mathrm{Pt}(100)$ terraces sites, leads eventually to the poisoning of the entire electrode. ${ }^{10}$ Although polycrystalline platinum electrodes are therefore not suited as catalysts for the reduction of acetone, there might be strategies to render them resilient against poisoning. This might be achieved by the preferential blocking of (100) terraces sites through the deposition of adatoms or by the generation of size- and shapecontrolled Pt nanoparticles featuring only (100) terraces below the critical size needed for the decarbonylation of acetone. In a previous work, our group has shown that the extraordinary activity for bond breaking observed on $\mathrm{Pt}(100)$ electrodes is due to a geometric effect: ${ }^{31}$ The cleavage of the $\mathrm{C}-\mathrm{O}$ bond of dimethyl ether occurs, for instance, when $\mathrm{C}$ and $\mathrm{O}$ atoms bind to two opposing bridge sites. ${ }^{31}$ The corresponding ensemble only exists on the $\mathrm{Pt}(100)$ terrace and comprises 4 surface atoms. The fact that we do not observe any $\mathrm{C}-\mathrm{C}$ bond cleavage at the (100) step site suggest that the same ensemble as in ref 31 is needed to achieve the $\mathrm{C}-\mathrm{C}$ bond cleavage of acetone. In this context, it is also worth mentioning that our SERS results indicate the adsorption of acetone as the enol species in the $\mu^{2}\left(\mathrm{C}_{1}, \mathrm{C}_{2}\right)$ side-on geometry. Only when acetone adsorbs through the $\mathrm{C}=\mathrm{C}$ bond of its enol tautomer, does an adsorption geometry exist that is reminiscent of that realized for dimethyl ether, that is, only in such a geometry do the $\mathrm{C}$ atoms adsorb on opposing bridge sites. Such a geometry cannot be imagined when acetone adsorbs in an $\eta^{1}(\mathrm{O})$ end-on geometry observed in vacuo. Indeed, it is hard to imagine any form of $\mathrm{C}=\mathrm{C}$ bond activation through the action of the electrode surface when acetone only binds with the carbonyl oxygen to the electrode surface.

\section{CONCLUSION}

The stripping experiments conducted in this work show that dissociative acetone adsorption only occurs at the $\operatorname{Pt}(100)$ terrace sites. The formed adsorbate cannot be stripped reductively and is oxidized in the potential range between 0.6 (vs RHE) to $0.9 \mathrm{~V}$ (vs RHE). Together with our SERS and FTIR experiments, this suggests that acetone undergoes decarbonylation and forms $\mathrm{CO}$ at $\mathrm{Pt}(100)$ terraces. Acetone adsorbed to all other surface sites retains its molecular structure and can be stripped reductively prior to hydrogen evolution or oxidatively in the potential region of platinum oxide formation. Remarkably, decarbonylation of acetone does not occur at step sites with (100) geometry. This implies that dissociative acetone adsorption also requires a certain (100) terrace size with freely available $\mathrm{Pt}$ atoms. This is in line with the results presented by Hazzazi et al., who arrived at a similar conclusion for ethyl pyruvate. ${ }^{6}$ We suggest that cleavage of the $\mathrm{C}-\mathrm{C}$ bond requires adsorption of the $\mathrm{C}=\mathrm{C}$ bond of the enol tautomer in a geometry in which each of the $\mathrm{C}$ atoms binds to opposing bridge sites. Such a geometry only exists at $\mathrm{Pt}(100)$ terraces and comprises 4 surface atoms.

\section{ASSOCIATED CONTENT}

\section{Supporting Information}

The Supporting Information is available free of charge at https://pubs.acs.org/doi/10.1021/acs.jpcc.0c11360.

Additional CV data at $\mathrm{Pt}(911), \operatorname{Pt}(510)$, and $\mathrm{Pt}(533)$; additional FTIR data (PDF)

\section{AUTHOR INFORMATION}

\section{Corresponding Author}

Marc T. M. Koper - Leiden Institute of Chemistry, Leiden University, 2300 RA Leiden, The Netherlands; (1) orcid.org/ 0000-0001-6777-4594; Email: m.koper@lic.leidenuniv.nl

\section{Authors}

Christoph J. Bondue - Leiden Institute of Chemistry, Leiden University, 2300 RA Leiden, The Netherlands

Zhiqin Liang - Leiden Institute of Chemistry, Leiden University, 2300 RA Leiden, The Netherlands

Complete contact information is available at: https://pubs.acs.org/10.1021/acs.jpcc.0c11360

\section{Author Contributions}

The manuscript was written through contributions of all authors. All authors have given approval to the final version of the manuscript. 


\section{Notes}

The authors declare no competing financial interest.

\section{ACKNOWLEDGMENTS}

We gratefully acknowledge financial support from The Netherlands Organization for Scientific Research (NWO) in the framework of the fund New Chemical Innovations (project: 731.015.204 ELECTROGAS) with financial support from Akzo Nobel Chemicals, Shell Global Solutions, Magneto Special Anodes (Evoqua Water Technologies) and Elson Technologies, and Shell Global Solutions in the framework of the Advanced Research Center Chemical Building Blocks Consortium (ARC-CBBC).

\section{REFERENCES}

(1) Brown, T. R.; Brown, R. C. What role for the bioeconomy in an electrified transportation sector? Biofuels, Bioprod. Biorefin. 2017, 11, 363-372.

(2) Villalba, M.; del Pozo, M.; Calvo, E. J. Electrocatalytic hydrogenation of acetophenone and benzophenone using palladium electrodes. Electrochim. Acta 2015, 164, 125-131.

(3) Cantu, D. C.; Padmaperuma, A. B.; Nguyen, M.-T.; Akhade, S. A.; Yoon, Y.; Wang, Y.-G.; Lee, M.-S.; Glezakou, V.-A.; Rousseau, R.; Lilga, M. A. A Combined Experimental and Theoretical Study on the Activity and Selectivity of the Electrocatalytic Hydrogenation of Aldehydes. ACS Catal. 2018, 8, 7645-7658.

(4) Song, Y.; Sanyal, U.; Pangotra, D.; Holladay, J. D.; Camaioni, D. M.; Gutiérrez, O. Y.; Lercher, J. A. Hydrogenation of benzaldehyde via electrocatalysis and thermal catalysis on carbon-supported metals. J. Catal. 2018, 359, 68-75.

(5) Chadderdon, X. H.; Chadderdon, D. J.; Matthiesen, J. E.; Qiu, Y.; Carraher, J. M.; Tessonnier, J.-P.; Li, W. Mechanisms of Furfural Reduction on Metal Electrodes: Distinguishing Pathways for Selective Hydrogenation of Bioderived Oxygenates. J. Am. Chem. Soc. 2017, 139, 14120-14128.

(6) Hazzazi, O. A.; Huxter, S. E.; Taylor, R.; Palmer, B.; Gilbert, L.; Attard, G. A. Electrochemical studies of irreversibly adsorbed ethyl pyruvate on $\mathrm{Pt}\{\mathrm{hkl}\}$ and epitaxial $\mathrm{Pd} / \mathrm{Pt}\{\mathrm{hkl}\}$ adlayers. J. Electroanal. Chem. 2010, 640, 8-16.

(7) Rees, N. V.; Taylor, R. J.; Jiang, Y. X.; Morgan, I. R.; Knight, D. W.; Attard, G. A. In Situ Surface-Enhanced Raman Spectroscopic Studies and Electrochemical Reduction of $\alpha$-Ketoesters and Self Condensation Products at Platinum Surfaces. J. Phys. Chem. C 2011, $115,1163-1170$.

(8) Kwon, Y.; de Jong, E.; Raoufmoghaddam, S.; Koper, M. T. M. Electrocatalytic hydrogenation of 5-hydroxymethylfurfural in the absence and presence of glucose. ChemSusChem 2013, 6, 1659-1667.

(9) Kwon, Y.; Birdja, Y. Y.; Raoufmoghaddam, S.; Koper, M. T. M. Electrocatalytic hydrogenation of 5-hydroxymethylfurfural in acidic solution. ChemSusChem 2015, 8, 1745-1751.

(10) Bondue, C. J.; Calle-Vallejo, F.; Figueiredo, M. C.; Koper, M. T. M. Structural principles to steer the selectivity of the electrocatalytic reduction of aliphatic ketones on platinum. Nat. Catal 2019, $2,243-250$.

(11) Bondue, C. J.; Koper, M. T. M. Electrochemical Reduction of the Carbonyl Functional Group: The Importance of Adsorption Geometry, Molecular Structure, and Electrode Surface Structure. J. Am. Chem. Soc. 2019, 141, 12071-12078.

(12) Bondue, C. J.; Koper, M. T. M. A mechanistic investigation on the electrocatalytic reduction of aliphatic ketones at platinum. J. Catal. 2019, 369, 302-311.

(13) de Hemptinne, X.; Schunck, K. Electrochemical reduction of acetone. Electrocatalytic activity of platinized platinum. Trans. Faraday Soc. 1969, 65, 591.

(14) Bänsch, B.; Härtung, T.; Baltruschat, H.; Heitbaum, J. Reduction and oxidation of adsorbed acetone at platinum electrodes studied by DEMS. J. Electroanal. Chem. Interfacial Electrochem. 1989, $259,207-215$.

(15) Guan, S.; Donovan-Sheppard, O.; Reece, C.; Willock, D. J.; Wain, A. J.; Attard, G. A. Structure Sensitivity in Catalytic Hydrogenation at Platinum Surfaces Measured by Shell-Isolated Nanoparticle Enhanced Raman Spectroscopy (SHINERS). ACS Catal. 2016, 6, 1822-1832.

(16) Clavilier, J.; Armand, D.; Sun, S. G.; Petit, M. Electrochemical adsorption behaviour of platinum stepped surfaces in sulphuric acid solutions. J. Electroanal. Chem. Interfacial Electrochem. 1986, 205, 267-277.

(17) Zou, S.; Weaver, M. J. Surface-enhanced Raman scattering on uniform transition-metal films: toward a versatile adsorbate vibrational strategy for solid-nonvacuum interfaces? Anal. Chem. 1998, 70, $2387-2395$.

(18) Lai, S. C. S.; Kleyn, S. E. F.; Rosca, V.; Koper, M. T. M. Mechanism of the Dissociation and Electrooxidation of Ethanol and Acetaldehyde on Platinum As Studied by SERS. J. Phys. Chem. C 2008, 112, 19080-19087.

(19) Iwasita, T.; Nart, F. C.; Vielstich, W. An FTIR Study of the Catalytic Activity of a 85:15 Pt:Ru Alloy for Methanol Oxidation. Berichte der Bunsengesellschaft für physikalische Chemie 1990, 94, $1030-1034$

(20) Chen, X.; McCrum, I. T.; Schwarz, K. A.; Janik, M. J.; Koper, M. T. M. Co-adsorption of Cations as the Cause of the Apparent $\mathrm{pH}$ Dependence of Hydrogen Adsorption on a Stepped Platinum SingleCrystal Electrode. Angew. Chem., Int. Ed. 2017, 56, 15025-15029.

(21) Jacobse, L.; Huang, Y.-F.; Koper, M. T. M.; Rost, M. J. Correlation of surface site formation to nanoisland growth in the electrochemical roughening of $\mathrm{Pt}(111)$. Nat. Mater. 2018, 17, 277282.

(22) García, G.; Silva-Chong, J.; Rodríguez, J. L.; Pastor, E. Spectroscopic elucidation of reaction pathways of acetaldehyde on platinum and palladium in acidic media. J. Solid State Electrochem. 2014, 18, 1205-1213.

(23) Abd-El-Latif, A. A.; Mostafa, E.; Huxter, S.; Attard, G.; Baltruschat, $\mathrm{H}$. Electrooxidation of ethanol at polycrystalline and platinum stepped single crystals: A study by differential electrochemical mass spectrometry. Electrochim. Acta 2010, 55, 7951-7960.

(24) Del Colle, V.; Souza-Garcia, J.; Tremiliosi-Filho, G.; Herrero, E.; Feliu, J. M. Electrochemical and spectroscopic studies of ethanol oxidation on Pt stepped surfaces modified by tin adatoms. Phys. Chem. Chem. Phys. 2011, 13, 12163-12172.

(25) Lai, S. C. S.; Koper, M. T. M. Electro-oxidation of ethanol and acetaldehyde on platinum single-crystal electrodes. Faraday Discuss. 2009, 140, 399-416.

(26) Joerges, M.; Nikuradse, A. Beobachtungen an den RamanLinien binärer und ternärer Gemische von Aceton, Methylalkohol und Schwefelkohlenstoff. Z. Naturforsch., A: Phys. Sci. 1950, 5, 25-34.

(27) Vannice, M. A.; Erley, W.; Ibach, H. A RAIRS and HREELS study of acetone on $\mathrm{Pt}(111)$. Surf. Sci. 1991, 254, 1-11.

(28) Xu, M.; Huai, X.-L.; Liu, H. Role of Keto-Enol Isomerization on Surface Chemistry and Hydrogenation of Acetone on Pt(111): A DFT study. Ind. Eng. Chem. Res. 2014, 53, 5451-5454.

(29) Jeffery, E. L.; Mann, R. K.; Hutchings, G. J.; Taylor, S. H.; Willock, D. J. A density functional theory study of the adsorption of acetone to the (111) surface of Pt: Implications for hydrogenation catalysis. Catal. Today 2005, 105, 85-92.

(30) Lebedeva, N. P.; Koper, M. T. M.; Feliu, J. M.; van Santen, R. A. Role of Crystalline Defects in Electrocatalysis: Mechanism and Kinetics of CO Adlayer Oxidation on Stepped Platinum Electrodes. J. Phys. Chem. B 2002, 106, 12938-12947.

(31) Li, H.; Calle-Vallejo, F.; Kolb, M. J.; Kwon, Y.; Li, Y.; Koper, M. T. M. Why $\left(\begin{array}{lll}1 & 0 & 0\end{array}\right)$ terraces break and make bonds: oxidation of dimethyl ether on platinum single-crystal electrodes. J. Am. Chem. Soc. 2013, 135, 14329-14338. 